CARBON IN THE GEOBIOSPHERE

- EARTH'S OUTER SHELL - 


\section{TOPICS IN GEOBIOLOGY}

\section{Series Editors:}

Neil H. Landman, American Museum of Natural History, New York, New York, landman@amnh.org

Douglas S. Jones, University of Florida, Gainesville, Florida, dsjones@,flmnh.ufl.edu

Current volumes in this series

Volume 25: $\quad$ Carbon in the Geobiosphere -- Earth's Outer Shell -Fred T. Mackenzie and Abraham Lerman Hardbound, ISBN 1-4020-4044-X, 2006

Volume 24: $\quad$ Studies on Mexican Paleontology

Francisco J. Vega, Torrey G. Nyborg, María del Carmen Perrilliat, Marison Montellano-Ballesteros, Sergio R.S. Cevallos-Ferriz and Sara A. Quiroz-Barroso Hardbound, ISBN 1-4020-3882-8, October 2005

Volume 23: $\quad$ Applied Stratigraphy

Eduardo A. M. Koutsoukos

Hardbound, ISBN 1-4020-2632-3, January 2005

Volume 22: $\quad$ The Geobiology and Ecology of Metasequoia

Ben A. LePage, Christopher J. Williams and Hong Yang

Hardbound, ISBN 1-4020-2631-5, March 2005

Volume 21: High-Resolution Approaches in Stratigraphic Paleontology

Peter J. Harries

Hardbound, ISBN 1-4020-1443-0, September 2003

Volume 20: $\quad$ Predator-Prey Interactions in the Fossil Record

Patricia H. Kelley, Michal Kowalewski, Thor A. Hansen

Hardbound, ISBN 0-306-47489-1, January 2003

Volume 19: Fossils, Phylogeny, and Form

Jonathan M. Adrain, Gregory D. Edgecombe, Bruce S. Lieberman

Hardbound, ISBN 0-306-46721-6, January 2002

Volume 18: $\quad$ Eocene Biodiversity

Gregg F. Gunnell

Hardbound, ISBN 0-306-46528-0, September 2001

Volume 17: The History and Sedimentology of Ancient Reef Systems

George D. Stanley Jr.

Hardbound, ISBN 0-306-46467-5, November 2001

Volume 16: Paleobiogeography

Bruce S. Lieberman

Hardbound, ISBN 0-306-46277-X, May 2000

Volume 15: Environmental Micropaleontology

Ronald E. Martin

Hardbound, ISBN 0-306-46232-X, July 2000

Volume 14: Neogene, Paleontology of the Manonga Valley, Tanzania

Terry Harrison

Hardbound, ISBN 0-306-45471-8, May 1997

For detailed information on our books and series please visit: 


\section{Carbon in the Geobiosphere - Earth's Outer Shell -}

FRED T. MACKENZIE

Department of Oceanography,

School of Ocean and Earth Science and Technology,

University of Hawaii, Honolulu, U.S.A.

\author{
ABRAHAM LERMAN
}

Department of Geological Sciences,

Northwestern University,

Evanston, Illinois, U.S.A. 
A C.I.P. Catalogue record for this book is available from the Library of Congress.

ISBN-10 1-4020-4044-X (HB)

ISBN-13 978-1-4020-4044-3 (HB)

ISBN-10 1-4020-4238-8 (e-book)

ISBN-13 978-1-4020-4238-6 (e-book)

Published by Springer,

P. O. Box 17, 3300 AA Dordrecht, The Netherlands.

www.springer.com

Printed on acid-free paper

All Rights Reserved

(C) 2006 Springer

No part of this work may be reproduced, stored in a retrieval system, or transmitted

in any form or by any means, electronic, mechanical, photocopying, microfilming, recording

or otherwise, without written permission from the Publisher, with the exception

of any material supplied specifically for the purpose of being entered

and executed on a computer system, for exclusive use by the purchaser of the work. 


\section{Aims \& Scope Topics in Geobiology Book Series}

Topics in Geobiology series treats geobiology — the broad discipline that covers the history of life on Earth. The series aims for high quality, scholarly volumes of original research as well as broad reviews. Recent volumes have showcased a variety of organisms including cephalopods, corals, and rodents. They discuss the biology of these organisms - their ecology, phylogeny, and mode of life - and in addition, their fossil record - their distribution in time and space.

Other volumes are more theme based such as predator-prey relationships, skeletal mineralization, paleobiogeography, and approaches to high resolution stratigraphy, that cover a broad range of organisms. One theme that is at the heart of the series is the interplay between the history of life and the changing environment. This is treated in skeletal mineralization and how such skeletons record environmental signals and animal-sediment relationships in the marine environment.

The series editors also welcome any comments or suggestions for future volumes;

\section{Series Editors:}

Douglas S. Jones dsjones@flmnh.ufl.edu

Neil H. Landman landman@amnh.org 


\section{Preface}

What is the importance of carbon on Earth? Why at this time devote a book to its discussion? Carbon is essential in all biological processes and in a great variety of mineral and inorganic processes near the Earth's surface. Carbon is the chemical element that is the main building block of living organic matter, and no evidence has been found so far of the existence of non-carbon-bearing life forms. Carbon in the atmosphere and waters is critically important to plants that make their organic matter from carbon dioxide and water and produce oxygen in the presence of light and the nutrients nitrogen, phosphorus, and bioessential trace elements, in a process known as photosynthesis. In the absence of light, where life exists below the Earth's surface and in the deep ocean, carbon dioxide is also involved in the production of organic matter. In addition, carbon dioxide in the atmosphere acts as a greenhouse gas that helps maintain temperatures suitable to life and life processes as we know them and an equable climate. Furthermore, carbon dioxide dissolved in rain water makes an acidic solution which, when falling on land, leads to the weathering of minerals and rocks, erosion of land, and transport of dissolved and particulate materials to the ocean.

We chose for the title of this book Carbon in the Geobiosphere to convey the view that the naturally occurring inorganic and organic forms of carbon and, in particular, carbon dioxide always played an environmentally important role within that part of the planet Earth that is the home to all living organisms, collectively known as the biosphere. Most of the plants and animals in the biosphere inhabit the region of the Earth's surface that is affected by processes occurring beneath as well as above it. As the book focuses on the integrated, interactive system of the atmosphere, oceans, continental waters, living biota, soils, minerals and organic matter in sediments, and near-surface and deeper interior, we use the term Outer Shell of the Earth as extending from the surface to the base of the lithosphere, at a mean depth of $-150 \mathrm{~km}$, and to about $+30 \mathrm{~km}$ above the surface, a layer that contains most of the mass of the atmosphere. This shell comprises the geobiosphere with the lower atmosphere, continental, subsurface, and oceanic waters, the biosphere, and the sedimentary and crystalline lithosphere that contain carbon or react chemically with its species in the gaseous phase and natural waters. Among all the organisms, from bacteria to plants and animals, the humans have so far been the strongest and fastest agents of environmental change that affects the geobiosphere. The human species as a geologic agent modifies the Earth's surface environment not only through emissions of gases from the burning of fossil fuels, but also through numerous industrial and agricultural activities that lead to changes in the Earth's vegetation cover, the atmosphere, the quality of soils and groundwaters, concentration of various metals in the geobiosphere, changes in the water regime of rivers and lakes, and a variety of chemical and biological changes that are broadly known as pollution. Such human-induced changes affect the cycles of carbon and other nutrient elements linked to it that are of fundamental importance to life on Earth. 
A great deal of attention has been paid in recent years to issues associated with the accumulation of carbon dioxide in the atmosphere, sources of emissions of the gas to the atmosphere and its removal processes, and the future time course of accumulation under different scenarios of growth of the human population and its use of fossil fuels, forest materials, and other natural resources. Human concerns about global warming have become a part of everyday discourse on how increasing carbon dioxide levels might affect the future climate of the world and what are the possible environmental, social, and economic implications of climatic change for human societies worldwide and for different nations of the world. This attention has led to a strong growth and diversification in scientific research and literature on the history and present situation regarding carbon dioxide in the Earth's atmosphere, and a search for reliable indicators in the geological record of past atmospheric carbon dioxide concentrations.

The issues of carbon dioxide in the atmosphere and its potential effects on the global climate represent changes that are gradual but concern all of humankind. Thus it is understandable that responses to the carbon dioxide accumulation in the atmosphere and its future consequences are, and will be, driven to a large extent in the near future by economic, social, and political considerations of societies in different regions of the world. However, for humans to be informed about the basic environmental issue of global warming, it takes considerably more insight into the functioning of the planet Earth than can be gained from reading the popular press, or from other news media, to understand why and how the concentration of carbon dioxide in the atmosphere - that is a relatively very small reservoir of carbon on a global scale - has been changing in the course of Earth's history, and what were and will be the consequences of such changes. The time scale of anthropogenic emissions of carbon dioxide from the increasing consumption of wood and natural biomass, coal, oil, and natural hydrocarbon gases includes less than three centuries of the present industrial age. The effects of these emissions on the chemical composition of the atmosphere and other processes taking place on the Earth's surface can be measured against the longer-term changes that have been occurring in the atmosphere, and the water, soils, rocks, and biota exposed to it.

In considering the geobiosphere and the Earth's outer shell, we provide in Chapter 1 of this book an overview of its structure at scales ranging from the Earth's dimensions to the atomic dimensions of the constituents of the atmosphere, water, and crustal rocks, and also give an outline of the global carbon cycle, its major reservoirs, and the fluxes between them. Because of the importance of fossil fuels to our technological society, the occurrences of these forms of carbon are also reviewed in the chapter. It is emphasized that the global cycles of carbon and many other elements are driven by biological and inorganic geochemical processes. The term biogeochemical cycle that describes the environmental reservoirs and flows of materials between them reflects the joint role of these processes in the environment.

The long period of about 600 million years since the formation of the Earth to the first records of life is addressed in Chapter 2. The primordial atmosphere of the Earth was largely a product of degassing of the Earth's interior, its chemical composition was very different from that of the present-day atmosphere, and its temperature and pressure were likely to have been considerably higher early in Earth's history. We consider in Chapter 2 the early stages of the chemical composition of ocean water that was to a large 
extent controlled by dissolution of hydrogen chloride, carbon dioxide, and hydrogen sulfide into the hydrosphere and its subsequent reactions with the early lithosphere of the Earth. We also address the question of the occurrence of the gases methane $\left(\mathrm{CH}_{4}\right)$, as a chemically reduced form of carbon, and its oxidized form, carbon dioxide $\left(\mathrm{CO}_{2}\right)$. The formation of living organic matter by chemical synthesis and, later, by photosynthesis signals the end of the prebiotic stage of Earth's history, and a discussion of the basic chemical reactions that lead to the formation of organic matter concludes this chapter.

In Chapter 3 we address the fundamentals of the thermal energy balance between the incoming solar radiation and the Earth's surface, and the greenhouse effect of the atmosphere that is responsible for a warmer Earth's surface than it would be without the atmosphere. We also point out that the term "greenhouse effect" is something of a misnomer, despite its well-rooted and widely accepted usage everywhere. As a reminder of the historical background, we discuss an early treatment of the greenhouse warming of the Earth's atmosphere by Milutin Milankovitch in 1920-1930, and conclude the chapter with a summary of the recent evidence of the radiation forcing and temperature increase projected for the 21 st century, the so-called enhanced greenhouse effect.

The chemical and mineralogical properties of the three common carbonate minerals of calcite, aragonite, and dolomite are discussed in Chapter 4. The chapter describes the mineral characteristics of pure and magnesium-containing calcites, pure and strontiumcontaining aragonites, and dolomites with slightly variable calcium and magnesium content. The chapter also discusses the essentials of the solid solution theory, and the theoretical and experimental treatment of the dissolution and precipitation rates of these minerals at the conditions approximating those of the Earth's outer shell. Because much of the present mass of limestone in the sedimentary record was formed by marine organisms as skeletal parts and shells, the biogenic and non-biogenic occurrences of these minerals, as well as the relevance of this information to other processes on Earth, are also briefly discussed in this chapter.

The behavior of inorganic carbon as $\mathrm{CO}_{2}$ and other carbonate ionic species in fresh and ocean waters is treated in Chapter 5. We discuss the implications of the fact that in modern times, part of the $\mathrm{CO}_{2}$ from industrial and land-use emissions to the atmosphere accumulated in the ocean. We provide calculations for the average thickness of the surface ocean layer that absorbed this $\mathrm{CO}_{2}$, showing its dependence on how the carbonate equilibria respond to changing environmental conditions and turbulent mixing and water transport in the ocean. We also consider the implications of the fact that the rate of calcite dissolution is related to the degree of carbonate mineral saturation and that although surface seawater is everywhere supersaturated with respect to calcite, calcite dissolves at depth in the oceans because of decreasing saturation state due to increasing internal $P_{\mathrm{CO}_{2}}$ and pressure with depth. Considering the extensive research activity behind the issue of possible storage of industrial $\mathrm{CO}_{2}$ as liquefied gas in the deep ocean, we discuss in this chapter the properties of the $\mathrm{CO}_{2}$ liquid and hydrate phases in the environment of ocean water. We also show that because $\mathrm{CO}_{2}$ forms in the precipitation and storage of mineral $\mathrm{CaCO}_{3}$, it is a possible source of emission of $\mathrm{CO}_{2}$ gas to the atmosphere from ocean water, where the outward directed flux might be in part counteracted by biological primary production and storage of organic carbon in sediments. 
The isotopic fractionation of the two stable isotopes of carbon, ${ }^{13} \mathrm{C}$ and ${ }^{12} \mathrm{C}$, is treated in Chapter 6. The equilibrium fractionation is discussed for the inorganic system of gaseous $\mathrm{CO}_{2}$, aqueous carbonate species, and mineral $\mathrm{CaCO}_{3}$ at the environmental conditions of the Earth's surface. The non-equilibrium or kinetic fractionation occurs in the photosynthetic production of organic matter and other biologically mediated reactions. The ${ }^{13} \mathrm{C} /{ }^{12} \mathrm{C}$ fractionation is considered the first evidence for the occurrence of life on the early Earth, and it is also an indicator of the origin of various organic and mineral substances. In addition, the geologically established long-term record of the isotopically fractionated carbon in limestones and sedimentary organic matter provides bounds on the origin and evolution of the biosphere and the history of oxygen accumulation in the atmosphere.

Chapters 7 through 9 deal with three important parts of the global carbon cycle. First, in Chapter 7 we discuss the storage of carbon in sediments and the recycling that returns it to the atmosphere, biosphere, and ocean, as well as the sedimentary history of carbonate rocks that constitute about $80 \%$ of the mass of sedimentary carbon. The carbonate sedimentary record, its mineral composition, and isotopic ratios of ${ }^{13} \mathrm{C} /{ }^{12} \mathrm{C}$ and ${ }^{18} \mathrm{O} /{ }^{16} \mathrm{O}$ provide a picture of long-term trends of evolution of ocean water and atmosphere that is supplemented by the isotopic evidence of strontium $\left({ }^{87} \mathrm{Sr} /{ }^{86} \mathrm{Sr}\right)$ in limestones, sulfur $\left({ }^{34} \mathrm{~S} /{ }^{32} \mathrm{~S}\right)$ in the sulfate minerals of evaporitic rocks, and the chemical composition of fluid inclusions in $\mathrm{NaCl}$ crystals in evaporites. This chapter also begins to address the evolving carbon cycle since Hadean time. Next, Chapter 8 focuses on the dissolution of sedimentary and crustal rocks in mineral reactions with acidic, $\mathrm{CO}_{2}$ containing atmospheric precipitation and groundwaters. This process is the first step in the transport of dissolved and particulate materials from land to the ocean by the release due to weathering of the main constituents of river waters. The weathering rates of the individual rock types that produce the global average river water, relative stabilities of rock-forming minerals, and consumption of $\mathrm{CO}_{2}$ in weathering are also discussed in this chapter, where we emphasize the importance of the $\mathrm{CO}_{2}$ flux in weathering in the global carbon cycle. The third part, addressed in Chapter 9, is the processes in the oceanic coastal margin that corresponds roughly to an area equivalent to about $8 \%$ of the ocean surface area. In this region there occurs at present a significant delivery of dissolved and particulate materials, an important part of oceanic primary production, storage of land-derived carbon, and calcium carbonate sequestration. The important processes in this relatively small area of the global coastal ocean are the remineralization of organic matter produced in situ and transported from land, the production of $\mathrm{CaCO}_{3}$ minerals of different solubilities (calcite, aragonite, and magnesian calcites of variable magnesium content), and the changes in biological production and calcification that are expected due to the rising atmospheric $\mathrm{CO}_{2}$ concentration that lowers the degree of saturation of ocean water with respect to the different carbonate minerals ("ocean acidification"). Combinations of these factors and physical mixing of the water masses determine the role of the coastal ocean as either a source or sink of atmospheric $\mathrm{CO}_{2}$.

Building on the preceding chapters, Chapter 10 presents the major aspects of the evolving carbon cycle since geologically distant to more recent time. The chapter starts with the earliest Eon of the Earth's history, the Hadean, and ends in the Pleistocene and Holocene Epochs, and the time of the last glacial to interglacial transition. This 
chapter draws on the simple picture of the carbon cycle that began in Chapter 1 and the primordial Earth, discussed in Chapter 2, expands it from the material given in the succeeding chapters, and presents our thoughts on the main driving mechanisms of the carbon cycle and the evolution of the ocean-atmosphere-biosphere-sediment system through geologic time.

Chapter 11 discusses the global carbon cycle in the Anthropocene, the period of the industrial age that started about 250 years ago. Because the Anthropocene is very likely to continue into the future, the chapter also considers the last two to three centuries of environmental change in terms of what might lie ahead. The effect of the carbon cycle on climate is only one important aspect of this global change. The human-produced perturbation of the global carbon cycle by the burning of fossil fuels and emissions from land-use has far-reaching effects on the linkages between the carbon cycle and the nutrient nitrogen and phosphorus cycles that are its drivers.

The literature dealing with the past, present, and future of carbon in the geobiosphere and the Earth's outer shell is very extensive. We attempted to cite those publications that bear directly on the ideas, factual material, and data in the diverse topics that we discuss in the book, but even the more than 700 bibliographic entries, from the $1840 \mathrm{~s}$ to the present, are only an incomplete list. Any errors of omission in the choice and coverage of the subject matter and in the recognition of other authors' contributions in the different fields are entirely ours.

The past and the future are usually studied by means of models of different degrees of complexity. The models are useful to our understanding of the relative magnitude and importance of the different geological, physical, chemical, and biological processes that control the distribution of carbon, and to our ability to describe the past and, at least to some extent, the future. The predictive ability of any model has a great value in forecasting and planning for the future, particularly for the processes that have a human dimension and affect the fabric of human societies. However, these useful features of models encounter serious obstacles because of the often-unforeseen developments in the future that do not conform to the basic assumptions and mechanisms of the models. Therefore our approach in this book is to discuss the fundamental principles of the biogeochemical cycling of carbon and give examples of how they contribute to our understanding of an integrated global picture that has been only recently affected by humans as a geologic agent.

It is our anticipation that this book will serve mainly as a reference text for Earth, ocean, and environmental scientists from various subdisciplines who might be interested in an overview of the carbon cycle and behavior of carbon dioxide, and the effects humans are having on them. Parts of this book have already been used by the authors as material for classroom discussion, so the book might also serve a one-semester course at the upper-undergraduate or graduate level addressing the behavior of the carbon cycle and its human modifications.

April 2006

$$
\text { A. L. }
$$

Evanston, Illinois
April 2006

F. T. M.

Honolulu, Hawaii 


\section{Acknowledgements}

The beginning of this book was a suggestion of Kenneth Howell, editor at Plenum Publishing in New York, to Fred Mackenzie to write a book on the subject of carbon dioxide in Earth's history. After we agreed to do this and a hesitant and slow start, the writing progressed along with a series of editorial transmutations that saw the publisher's name change from Plenum to Kluwer Academic and finally to Springer, in the course of which Ken Howell moved to another position and the editing functions were assumed first by Anna Besse-Lototskaya, and later by Tamara Welschot, and Senior Editorial Assistant Judith Terpos, of the Springer Paleo-Environmental Sciences Department at Dordrecht. We thank Ken, the original editor, his successors in the new organization, and Judith for their encouragement and patience through the time of writing this book and in getting it ready for publication.

We owe a debt of gratitude to many individuals at many institutions for their advice and help in providing us with information, literature references, data, and permissions to cite them. We are especially indebted to Lee R. Kump (The Pennsylvania State University) and Robert Raiswell (University of Leeds) for their review of the initial complete manuscript of this book. Their insights and constructive comments helped us a great deal in improving the presentation and content of the book. Within our individual universities and at other institutions, we thank the following, in alphabetical order.

At Northwestern University: Emile A. Okal, for his ever-readiness to respond helpfully and without regard to the impediment of the distance between himself and A. L. that extended sometimes to seven orders of magnitude (in meters), and other members of the Department of Geological Sciences whose bookshelves and reprint files were always open to us. A. L. is particularly greatful to former and current graduate students Benjamin C. Horner-Johnson, Robert E. Locklair, and Lingling Wu for discussions of the various subjects covered in the book, and to the students in his geochemistry class who were a helpful source of literature references. F. T. M. especially thanks Donna Jurdy, former Chair, and the members of the faculty for giving him the opportunity to be in residence at Northwestern for spring quarters and the unbridled time to write parts of this book.

At the University of Hawaii, Manoa: Michael O. Garcia, Yuan-Hui Telu Li, Christopher Measures, Michael J. Mottl, Brian N. Popp, Francis J. Sansone, Jane S. Schoonmaker, and Richard E. Zeebe. F. T. M. is very grateful to his current and former students, especially Andreas Andersson, Rolf Arvidson, Kathryn Fagan, Michael Guidry, Daniel Hoover, François Paquay, Stephanie Ringuet, Christopher Sabine, Katsumasa Tanaka, and Leah May Ver, for their intellectual interactions, and to the students in his classes who caught misprints in the text. A. L. also thanks the Marine Geology and Geochemistry Division of the Department of Oceanography for providing him the space and support to write unencumbered during the early stages in the development of this book. 
At the Centre de Géochimie de la Surface/C.N.R.S., Strasbourg: Norbert Clauer, the former Director of the Center, for his hospitality and extension of the Center's facilities to A. L., while on a sabbatical leave; to Bertrand Fritz, François Gauthier-Lafaye, Philip Meribelle, François Risacher, Claude Roquin, and Peter Stille for discussion of the various subjects dealt with in the book; and to Alain Clement for his continued support in making the computer systems function.

At other institutions: Alberto Borges (Université de Liège), Peter G. Brewer (Monterey Bay Aquarium Research Institute), Ken Caldeira (Department of Global Ecology, Carnegie Institution, Stanford, Calif.), Lei Chou (Université Libre de Bruxelles), Ian D. Clark (University of Ottawa), Tyler B. Coplen (U. S. Geological Survey), William P. Dillon (U. S. Geological Survey), James I. Drever (University of Wyoming), the late Michel Frankignoulle (Universite de Liège), Jean-Pierre Gattuso (Laboratoire d'Océanographie, Villefranche-sur-Mer, France), Harold C. Helgeson (University of California, Berkeley), Jochen Hoefs (Universität Göttingen), Dieter M. Imboden (Eidgenössische Technische Hochschule Zürich), Stephan Kempe (Technische Universität Darmstadt), John W. Kimball (Andover, Mass.), Stephen H. Kirby (U. S. Geological Survey), Timothy R. Klett (U. S. Geological Survey), Keith H. Kvenvolden (U. S. Geological Survey), Frank Peeters (Limnologisches Institut, Universität Konstanz), Edward T. Peltzer (Monterey Bay Aquarium Research Institute), Jean-Luc Probst (Ecole Nationale Supérieure Agronomique de Toulouse), Karsten Pruess (Lawrence Berkeley National Laboratory), Christophe Rabouille (Laboratoire des Sciences du Climat et de l'Environnement, Gif-sur-Yvette, France), John A. Ripmeester (National Research Council, Ottawa), Mikhail N. Shimaraev (Limnological Institute, Irkutsk), Stefan Sienell (Director of the Archives, Österreichische Akademie der Wissenschaften, Wien), Francesca A. Smith (Pennsylvania State University), Stephen V. Smith (Centro de Investigación Cientifíca y de Educatión Superior de Ensenada, Mexico), Roland Span (Universität Paderborn), the late Roland Wollast (Université Libre de Bruxelles), and Choong-Shik Yoo (Lawrence Livermore National Laboratory).

For help in the linguistic quandaries of Latin and Greek, we thank Daniel H. Garrison, of the Classics Department at Northwestern, and for additional advice on the use of ancient and modern Greek terms we thank Katerina Petronotis, of the Ocean Drilling Program, Texas A\&M University. Our literature searches and finding of publications long out of print or those held by a small number of libraries worldwide were greatly facilitated by the help received from Anna Ren, Geological Sciences librarian, and the dedicated personnel of the Interlibrary Loan Department at Northwestern; at the University of Hawaii, by Kathy Kozuma, secretary, and Jennifer Cole-Conner and Kellie Gushikan, student assistants, and University Library staff; and at the Universite Louis Pasteur, Strasbourg, by Betty Kieffer, librarian of the Institut de Géologie, and Janine Fischbach, librarian of the Institut de Physique du Globe, all of whom we thank wholeheartedly for the logistic support and library research.

We are grateful to the following persons and organizations for permissions to cite freely unpublished or copyrighted materials: American Association for the Advancement of Science, Washington, D. C., publishers of Science magazine (Fig. 2.6); American Institute of Biological Sciences, Washington, D. C., publishers of BioScience 
magazine (Figs. 6.2 and 6.5); Andreas J. Andersson, University of Hawaii (Figs. 5.6, 9.7, 9.8, 9.12, 9.17, and 9.19); Rolf S. Arvidson, Rice University (Fig. 10.3); Robert A. Berner, Yale University (Figs. 6.9B and 10.2); Nina Buchmann, Eidgenössische Technische Hochschule Zürich (Fig. 8.1); Bruce A. Buffett and David Archer, both of the University of Chicago (Fig. 5.10); Nelia W. Dunbar, New Mexico Bureau of Mining and Geology, Socorro, N. Mex. (photograph of Mount Erebus, front cover); Elsevier, publishers of Sedimentary Geology magazine (Fig. 9.18); Kathryn E. Fagan, University of Washington (Fig. 9.7); Richard G. Fairbanks, Lamont-Doherty Earth Observatory, Columbia University, Palisades, N.Y. (Fig. 9.3); Paul Falkowski, Rutgers University (Fig. 10.5); Graham D. Farquhar, Australian National University, Canberra (Fig. 6.3); Volker Hahn, Max Planck Institut für Biochemie, Jena (Fig. 8.1); John M. Hayes, Woods Hole Oceanographic Institution, Woods Hole, Mass. (Fig. 6.9); Ann Henderson-Sellers, Australian Nuclear Science and Technology Organisation, Lucas Heights, NSW, and Peter J. Robinson, University of North Carolina, Chapel Hill (Fig. 3.3A); Intergovernmental Panel on Climate Change, Geneva, Switzerland (Fig. 11.11); J. Richard Kyle, University of Texas, Austin (photograph of the El Capitan Permian reef, front cover, and related information); Kuo-Nan Liou, University of California, Los Angeles (Fig. 3.1); Gary Long, Energy Information Administration, U. S. Department of Energy (Fig. 1.6); C. Nicholas Murray, formerly of the Joint Research Centre, Ispra, Italy (Fig. 5.7); Nature Publishing Group, London, publishers of Nature magazine (Fig. 9.3); Emile A. Okal, Northwestern University (Fig. 1.2A); Marion H. O'Leary, California State University, Sacramento (Figs. 6.2 and 6.5); Norman R. Pace, University of Colorado, Boulder (Fig. 2.6); Adina Paytan, Stanford University (data in Fig. 7.14); Pearson Education, Harlow, Essex, U. K. (Fig. 3.3B); Peter W. Sloss, National Geophysical Data Center, Boulder, Colo. (Fig. 9.2); and Ján Veizer, University of Ottawa and Ruhr-Universität Bochum (Figs. 6.9A, 7.11, and 7.13).

And last, but far from least, thanks to Kare Berg from A. L. and to Judith Mackenzie from F. T. M., to each for her support, encouragement, and help during the writing of this book. This book is dedicated to the memory of our friend and research colleague over the years, Roland Wollast, of the Laboratoire d'Océanographie, Université Libre de Bruxelles, Belgium.

April 2006

A. L.

Evanston, Illinois
April 2006

F. T. M.

Honolulu, Hawaii 


\section{Picture Credits on the Front Cover}

\section{Top, from left to right:}

Mount Erebus, Antarctica, the southernmost volcano on Earth, elevation $3794 \mathrm{~m}$ above sea level $\left(77^{\circ} 32^{\prime} \mathrm{S}, 167^{\circ} 17^{\prime} \mathrm{E}\right)$, photographed in 1983 by Nelia Dunbar and published in Internet by the National Science Foundation and New Mexico Tech. http://www.ees.nmt.edu/Geop/mevo/mevomm/imagepages/dunbar/index.html Photograph courtesy of Dr. Nelia W. Dunbar, New Mexico Bureau of Geology and Mineral Resources, Socorro, N. Mex.

Earth photographed on 7 December 1972 by the Apollo 17 crew on the way to the Moon. NASA, http://visibleearth.nasa.gov/view_rec.php?id=1597

Reef limestone of Middle Permian Age, approximately 265 million years ago. El Capitan peak, Guadalupe Mountains, Texas, $2464 \mathrm{~m}$ above sea level $\left(31^{\circ} 53^{\prime} \mathrm{N}\right.$, $\left.104^{\circ} 51^{\prime} \mathrm{W}\right)$. http://www.utexas.edu/features/archive/2003/graphics/texas5.jpg Photograph and information courtesy of Professor J. Richard Kyle, Department of Geological Sciences, Jackson School of Geosciences, University of Texas, Austin, Tex.

True-color image of a portion of the Great Barrier Reef, off the coast of central Queensland, Australia, north of the Tropic of Capricorn, taken by NASA on 26 August 2000. The width of the reef zone is approximately $200 \mathrm{~km}$. NASA Earth Observatory, http://earthobservatory.nasa.gov/Newsroom/NewImages/images.php3?img_id=4797

\section{Center:}

Main features of the global carbon cycle at the Earth's surface. Based on Figures 1.4, 5.11, and 10.7 . 


\section{Contents}

Published Titles in Topics in Geobiology Book Series ii

Aims \& Scope Topics in Geobiology Book Series $\quad$ V

Preface vii

Acknowledgements xiii

Picture Credits $\quad$ xvii

$1 \quad$ Brief Overview of Carbon on Earth 1

1 An Unusual Look at Earth's Shells 2

2 Global Carbon Cycle 7

3 Fundamental Equation of a Cycle and Carbon Flows 14

4 Carbon in Fossil Fuels $\quad 18$

5 Feedbacks in the Carbon Cycle $\quad 21$

$2 \quad$ Earth's Volatile Beginnings $\quad 23$

1 The Major Volatiles $\quad 23$

2 Primordial Atmosphere-Ocean System $\quad 35$

3 Carbon Dioxide $\quad 40$

4 Summary and Speculations $\quad 45$

5 An Early Biosphere $\quad 49$

$3 \quad$ Heat Balance of the Atmosphere and Carbon Dioxide 61

1 Heat Sources at the Earth's Surface 62

2 Solar Heating and Radiation Balance $\quad 63$

3 Greenhouse Effect $\quad 69$

4 Temperature of a Prebiotic Atmosphere $\quad 80$

$5 \mathrm{CO}_{2}$ and Climate Change 83

4 Mineralogy, Chemistry, and Reaction Kinetics of the Major

Carbonate Phases $\quad 89$

1 Carbonate Minerals $\quad 90$

2 Calcites $\quad 93$

3 Dolomite 101

4 Aragonite 105

5 Carbonate Dissolution and Precipitation Kinetics 110

6 Carbonate Precipitation and Dissolution in Marine Ecosystems 115

7 Some Geological Considerations 116 
$5 \quad$ Carbon Dioxide in Natural Waters

1 Dissolution and Dissociation of $\mathrm{CO}_{2}$ in Water 124

$2 \mathrm{CO}_{2}$ Transfer from Atmosphere to Water 133

3 Calcite and Aragonite in Natural Waters 137

4 Degree of Saturation with Respect to Carbonate Minerals 138

$5 \mathrm{CO}_{2}$ Phases: Gas, Liquid, Hydrate, Ice 142

6 Air-Sea $\mathrm{CO}_{2}$ Exchange due to Carbonate and Organic Carbon Formation

6 Isotopic Fractionation of Carbon: Inorganic and

\section{Biological Processes}

1 Isotopic Species and Their Abundance 165

2 Isotopic Concentration Units and Mixing 167

3 Fractionation in Inorganic Systems 170

4 Photosynthesis and Plant Physiological Responses to $\mathrm{CO}_{2} \quad 174$

5 Isotopic Fractionation and ${ }^{13} \mathrm{C}$ Cycle 184

6 Long-Term Trends 188

7 Sedimentary Rock Record and Oceanic and

1 Geologic Time Scale and Sedimentary Record 194

2 The Beginnings of Sedimentary Cycling 195

3 Broad Patterns of Sediment Lithologies 197

4 Differential Cycling of the Sedimentary Mass and Carbonates 199

5 Sedimentary Carbonate System 202

6 Evaporites and Fluid Inclusions 208

7 Isotopic Trends 211

8 Summary of the Phanerozoic Rock Record in Terms of Ocean Composition

8 Weathering and Consumption of $\mathrm{CO}_{2} \quad 225$

1 Weathering Source: Sedimentary and Crystalline $\begin{array}{ll}\text { Lithosphere } & 226\end{array}$

2 Dissolution at the Earth's Surface 232

3 Mineral- $\mathrm{CO}_{2}$ Reactions in Weathering 237

$4 \mathrm{CO}_{2}$ Consumption from Mineral-Precipitation Model 242

$5 \mathrm{CO}_{2}$ Consumption from Mineral-Dissolution Model 247

6 Environmental Acid Forcing 252

9 Carbon in the Oceanic Coastal Margin 255

1 The Global Coastal Zone 256

2 Carbon Cycle in the Coastal Ocean 262

3 Inorganic and Organic Carbon 267

4 Marine Calcifying Organisms and Ecosystems 278

5 Present and Future of the Coastal Ocean Carbon System 284 
10 Natural Global Carbon Cycle through Time

1 The Hadean to Archean 289

2 The Archean to Proterozoic 293

3 The Phanerozoic $\quad 297$

4 Pleistocene to Holocene Environmental Change 303

11 The Carbon Cycle in the Anthropocene 319

1 Characteristics of the Anthropocene 319

2 Major Perturbations of the Carbon Cycle: 1850 to the Early $21 \mathrm{st}$ Century

3 Partitioning of the Carbon, Nitrogen, and Phosphorus Fluxes 326

4 The Fundamental Carbon Problem of the Future 336

Bibliographic References $\quad 343$

$\begin{array}{ll}\text { Index } & 383\end{array}$ 